\title{
Does newborn screening influence the young cystic fibrosis cohort included in national registries?
}

\author{
To the Editor:
}

Cystic fibrosis newborn screening (NBS), has not yet become a reality in all countries. We therefore compared the demographic and clinical characteristics of young children included in national cystic fibrosis registries from countries with and without NBS. We hypothesised that registries from countries with NBS would contain a higher proportion of milder and equivocal cases.

We analysed the 2011 data of five national cystic fibrosis registries (Australia with cystic fibrosis NBS since 2001; France with cystic fibrosis NBS since 2003; Belgium and Sweden without cystic fibrosis NBS; and the Netherlands with cystic fibrosis NBS since May 2011) and studied the cohort of children born in the years 2004-2011 in all countries i.e. children aged $<8$ years. We excluded cases missed by NBS in countries with screening (France, Australia), and cases diagnosed via local pilot screening projects in countries without NBS (Belgium, the Netherlands, Sweden). In every country, we studied the cohort of children aged $<8$ years: number as proportion of the entire national cystic fibrosis cohort; mean and median actual age; age at diagnosis; pancreatic status in 2011; and diagnostic test results. A sweat chloride value $>60 \mathrm{mmol} \cdot \mathrm{L}^{-1}$ or detection of two cystic fibrosis-causing mutations according to the CFTR2 project were taken as proof of diagnosis (www.cftr2.org; list July 22, 2013). Only sweat test results after pilocarpine iontophoresis (available in 2010 (82.1\%) out of 2448 patients were considered; in the $8.6 \%$ of these samples for which conductivity rather than chloride concentration was measured, a correction factor was applied [1].

Outcome was studied in 336 children aged 6 and 7 years with a class I to class III mutation on both alleles $(n=368)$ and lung function data available ( $n=336$ out of these 368). Patients were grouped in classes according to their cystic fibrosis transmembrane conductance regulator gene (CFTR) mutations [2], since these differ in effect on protein synthesis and function: class I to III mutations are on average associated with severe disease, whereas patients with at least one mutation of class IV and V and patients with sweat chloride below $60 \mathrm{mmol} \cdot \mathrm{L}^{-1}$ are known to have, on average, a better outcome [3] and a lower treatment burden [4]. We assessed forced expiratory volume in $1 \mathrm{~s}$ (FEV1) \% predicted (best of the year or at annual review in Sweden) according to Wang's equations and z-scores for height, weight and body mass index (BMI) using Centers for Disease Control and Prevention (CDC) reference values. Results are expressed as median (interquartile range) and proportions (95\% confidence intervals). Differences are considered significant when $95 \%$ confidence intervals do not overlap. To compare parameters between countries with and without NBS, t-tests, Wilcoxon signed rank tests and Chi-squared tests were used.

In total, 2448 children aged $<8$ years were included in the analysis (table 1). Excluded from analysis were: 108 cases in France not diagnosed via NBS (40 with meconium ileus and low immunoreactive trypsinogen and 68 missed by NBS); cases diagnosed via NBS pilot projects (56 in Belgium, 69 in the Netherlands and one in Sweden).

The proportion of subjects $<8$ years over the total number in the registry was significantly higher in France and Australia, compared with Belgium and the Netherlands (table 1). Similarly, the pooled number of young children as proportion of all subjects in the registries was higher in countries with NBS than countries without NBS. Median age, median age at diagnosis and prevalence of pancreatic insufficiency were all significantly lower in the young cohort from countries with NBS than without NBS.

@ERSpublications

National cystic fibrosis newborn screening programmes lead to changes in the composition of the CF registry cohort http://ow.ly/12o8304uinU

Cite this article as: De Boeck K, Munck A, de Monestrol I, et al. Does newborn screening influence the young cystic fibrosis cohort included in national registries?. Eur Respir J 2017; 49: 1600686 [https://doi. org/10.1183/13993003.00686-2016]. 
TABLE 1 Demographic data and diagnostic test results of children aged <8 years in national cystic fibrosis registries from countries with and without newborn screening

\begin{tabular}{|c|c|c|c|c|c|c|c|c|}
\hline & \multicolumn{3}{|c|}{ Countries with newborn screening } & \multicolumn{4}{|c|}{ Countries without newborn screening } & \multirow[t]{2}{*}{$p$-value ${ }^{\pi}$} \\
\hline & France & Australia & Pooled & Belgium & Netherlands & Sweden & Pooled & \\
\hline \multicolumn{9}{|l|}{ Demographic data } \\
\hline Subjects aged $<8$ years $n(\% ; 95 \% \mathrm{Cl})$ & $1289(22.0 ; 20.9-23.0)$ & $754(24.1 ; 22.6-25.6)$ & $22.7(21.8-23.6)$ & $129(13.4 ; 11.3-15.7)$ & $175(13.4 ; 11.6-15.4)$ & $101(18.0 ; 14.9-21.5)$ & $14.3(13.0-15.7)$ & $<0.001$ \\
\hline Age years median (interquartile range) & $4.4(2.4-6.2)$ & $4.3(2.4-6.1)$ & $4.3(2.4-6.2)$ & $4.8(2.3-6.6)$ & $5.1(3.5-6.3)$ & $4.3(2.8-6.2)$ & $4.9(2.8-6.4)$ & 0.007 \\
\hline $\begin{array}{l}\text { Age at diagnosis months median } \\
\text { (interquartile range) }\end{array}$ & $1.1(0.7-1.6)$ & $1.0(0.6-1.7)$ & $1.1(0.7-1.6)$ & $2.4(0.4-9.1)$ & $3.0(1.2-12.0)$ & $5.0(2.2-15.2)$ & $3.6(1.2-12.0)$ & $<0.001$ \\
\hline Pancreatic insufficiency $\%(95 \% \mathrm{Cl})$ & $81.5(79.3-83.6)$ & $83.0(80.1-85.7)$ & $80.9(79.1-82.5)$ & $93.0(87.2-96.8)$ & $89.1(83.6-93.0)$ & $93.7(86.8-97.8)$ & $91.6(88.5-94.1)$ & $<0.001$ \\
\hline Homozygous F508del \% (95\% Cl) & $43.3(40.6-46.0)$ & $48.4(44.8-52.0)$ & & $45.7(36.9-54.7)$ & $66.9(59.6-73.4)$ & $52.5(42.3-62.5)$ & & \\
\hline \multicolumn{9}{|l|}{ Diagnostic test results } \\
\hline Two CFTR mutations \% $(95 \%$ CI) & $98.9(98.2-99.4)$ & $84.4(81.6-86.9)$ & & $96.1(91.2-98.7)$ & $94.9(90.5-97.6)$ & $99.0(94.6-100)$ & & \\
\hline $\begin{array}{l}\text { Two cystic fibrosis-causing mutations } \\
\%(95 \% \mathrm{CI})\end{array}$ & $80.8(78.5-82.9)$ & $60.6(57.0-64.1)$ & & $86.8(79.7-92.1)$ & $89.1(83.6-93.0)$ & $94.1(87.5-97.8)$ & & \\
\hline No sweat test result \% $(95 \% \mathrm{Cl})$ & $2.3(1.6-3.3)$ & $41.6(38.1-45.3)$ & & $11.6(6.7-21.1)$ & $37.1(30.1-44.8)$ & $13.9(7.8-22.2)$ & & \\
\hline Sweat chloride $\leqslant 60 \mathrm{mmol} \cdot \mathrm{L}^{-1 \#} \%(95 \% \mathrm{Cl})$ & $19.1(17.0-21.4)$ & $13.0(10.0-16.5)$ & & $3.5(1.0-8.7)$ & $7.3(3.2-13.8)$ & $3.5(0.7-9.7)$ & & \\
\hline $\begin{array}{l}\text { Sweat chloride } \leqslant 60 \mathrm{mmol} \cdot \mathrm{L}^{-1} \text { and more } \\
\text { than two cystic fibrosis-causing } \\
\text { mutations } \%[95 \% \mathrm{CI}]\end{array}$ & $9.5(7.9-11.2)$ & $18.7(16.0-21.7)$ & $12.9(11.5-14.4)$ & $5.4(0.8-7.7)$ & $5.7(2.8-10.3)$ & 0 & $3.4(1.9-5.7)$ & $<0.001$ \\
\hline
\end{tabular}

Demographic data in national cystic fibrosis registries and diagnostic test results in children up to age 8 years from selected countries. Results per country and pooled for countries with and without newborn screening. "\#: \% based on the $82 \%$ of patients with sweat chloride reported; ${ }^{\uparrow}$ : $p$-values compare pooled data. 
The proportion of subjects with two CFTR mutations identified was lowest in Australia but did not differ between the four other countries. In France as well as Australia the proportion of subjects with two cystic fibrosis-causing mutations was lower than in the Netherlands and Sweden but not compared with Belgium. In all countries but France, the proportion of subjects without sweat chloride results reported was higher than $10 \%$. Countries with NBS included a higher proportion of subjects with a sweat chloride value below $60 \mathrm{mmol} \cdot \mathrm{L}^{-1}$ as well as with a sweat chloride value below $60 \mathrm{mmol} \cdot \mathrm{L}^{-1}$ plus less than two cystic fibrosis-causing mutations identified.

Outcomes were compared in 336 children with class I to III mutations on both alleles at a median (interquartile range) age of $6.7(6.3-7.1)$ years. Best FEV1 \% predicted (98.3 (88.6-107.5) \% predicted) as well as median BMI $z$-score $(-0.06(-0.71 ; 0.54)$ versus $0.09(-0.70 ; 0.66) ; \mathrm{p}=0.24)$ did not differ between countries with and without NBS. Median height $(0.11(-0.47-0.62)$ versus $-0.23(-0.91-0.35) ; \mathrm{p}=0.009)$ and weight $\mathrm{z}$-scores $(0.08(-0.31-0.63)$ versus $-0.25(-0.80-0.40) ; \mathrm{p}=0.004)$ were higher in countries without NBS and were the highest in the Netherlands.

We thus demonstrate that the young cohort included in cystic fibrosis registries differs between countries with and without NBS. Cystic fibrosis NBS allows making the diagnosis before 2 months of age, increases the proportion of young children in national registries and leads to early detection of children with cystic fibrosis and pancreatic sufficiency as well as children without full proof of a cystic fibrosis diagnosis. At age 6 and 7 years and limiting the group to patients with two (severe) mutations of class I to III, there was no difference in FEV1 \% predicted or nutritional status between countries with and without NBS.

When comparing outcome between registries, as is increasingly done for benchmarking and quality improvement $[5,6]$, one should be informed about the composition of the cohort. Children with an uncertain diagnosis of cystic fibrosis should not be included in the analysis of national cystic fibrosis registries, but this is not always adhered to [7]. We compared outcome only in children with an unequivocal diagnosis of cystic fibrosis and could not demonstrate a benefit of cystic fibrosis NBS. This does not at all mean that NBS does not lead to benefits. We know that the benefits of cystic fibrosis NBS, especially on the pulmonary outcome, only appear over a longer time period $[8,9]$ In addition, comparing height and weight using the Center for Disease Control reference values rather than country-specific reference values may mask benefits. Dutch subjects are known to be among the tallest in the world; hence, using universal CDC criteria rather than country specific reference values may mask benefits [10]. In such conditions, BMI values may give a better reflection of nutritional status and indeed these did not differ between registries with and without NBS. In addition, since we only analyse the weight, height and BMI at age 6 and 7 years, the early benefits of cystic fibrosis NBS on timely introduction of pancreatic enzymes and nutritional support are not captured.

Like any study, this one had limitations. Regional pilot projects existed in every country without national cystic fibrosis NBS, therefore, excluding subjects with a diagnosis via NBS in non-screening countries and subjects missed by NBS in screening countries appeared the only solution. A retrospective registry data analysis may suffer from differences between countries and even between sites within countries in data collection, use of diagnostic tests and test reporting. Missing data concerning diagnostic test results, may lead to overestimation of the number of subjects not meeting diagnostic criteria. We previously already pointed out the relatively high number of missing diagnostic data in national cystic fibrosis registries [11]. Quality control may differ between registries: some may exclude subjects in whom the diagnosis was not confirmed (such as Sweden) whereas others may accept all subjects reported by clinicians as having cystic fibrosis into the registry.

In conclusion, with the advent of cystic fibrosis NBS, the composition of the cystic fibrosis registry cohort changes: the relative number of young subjects increases, as will the number of young subjects with pancreatic sufficiency and even subjects with an unclear diagnosis. Guidance as to who should be included and analysed in a cystic fibrosis registry is needed, especially if data are used to track improvements in outcome. Careful consideration of the subjects included in cystic fibrosis registries is important when registry data is used for benchmarking between countries.

Kris De Boeck ${ }^{1}$, Anne Munck ${ }^{2,3}$, Isabelle de Monestrol $^{4}$, Vincent Gulmans ${ }^{5}$, Lydie Lemonnier ${ }^{6}$, Peter G. Middleton ${ }^{7}$, Simeon Wanyama ${ }^{8}$ and Muriel Thomas ${ }^{8}$

${ }^{1}$ Dept of Pediatrics, University of Leuven, Leuven, Belgium. ${ }^{2}$ Association Française Dépistage Prévention Handicap Enfant, Paris, France. ${ }^{3} \mathrm{CF}$ centre, Assistance-publique Hôpitaux de Paris, Université Paris, Hôpital Robert Debré, Paris, France. ${ }^{4}$ Swedish Cystic Fibrosis Registry, Karolinska Institutet, Stockholm, Sweden. ${ }^{5}$ Dutch CF Foundation (NCFS), Baarn, The Netherlands. ${ }^{6}$ French CF registry, Vaincre la mucoviscidose, Paris, France. ${ }^{7}$ Australian CF registry, Sydney, Australia. ${ }^{8}$ Belgian Cystic Fibrosis Registry, Scientific Institute of Public Health (WIV-ISP), Brussels, Belgium.

Correspondence: Kris De Boeck, Dept of Pediatrics, University of Leuven, Herestraat 49, 3000 Leuven, Belgium.

E-mail: Christiane.deboeck@uzleuven.be 
Received: Dec 082015 | Accepted after revision: Sept 112016

Conflict of interest: Disclosures can be found alongside this article at erj.ersjournals.com

Acknowledgements: All patients, cystic fibrosis centre directors and personnel who contribute to national cystic fibrosis registries.

\section{References}

1 Nguyen-Khoa T, Borgard JP, Marchand M, et al. Qualités analytiques des techniques de dosage et comparaison des procédures utilisées pour le test de la sueur. [Analytical quality of assays and comparison of procedures for the sweat test]. Ann Biol Clin 2012; 70: 5-12.

2 De Boeck K, Zolin A, Cuppens $\mathrm{H}$, et al. The relative frequency of CFTR mutation classes in European patients with cystic fibrosis. J Cyst Fibros 2014; 13: 403-409.

3 Goubau C, Wilschanski M, Skalická V, et al. Phenotypic characterisation of patients with intermediate sweat chloride values: towards validation of the European diagnostic algorithm for cystic fibrosis. Thorax 2009; 64: 683-689.

4 Dewulf J, Vermeulen F, Wanyama S, et al. Treatment burden in patients with at least one class IV or V CFTR mutation. Pediatric Pulmonol 2015; 50: 1230-1236.

5 Boyle MP, Sabadosa KA, Quinton HB, et al. Key findings of the US Cystic Fibrosis Foundation's clinical practice benchmarking project. BMJ Qual Saf 2014; 23: i15-i22.

6 Martin B, Schechter MS, Jaffe A, et al. Comparison of the US and Australian cystic fibrosis registries: the impact of newborn screening. Pediatrics 2012; 129: e348-e355.

7 Ren CL, Fink AK, Petren K, et al. Outcomes of infants with indeterminate diagnosis detected by cystic fibrosis newborn screening. Pediatrics 2015; 135: e1386-e1392.

8 Waters DL, Wilcken B, Irwig L, et al. Clinical outcomes of newborn screening for cystic fibrosis. Arch Dis Child Fetal Neonatal Ed 1999; 80: F1-F7.

9 McKay KO, Waters DL, Gaskin KJ. The influence of newborn screening for cystic fibrosis on pulmonary outcomes in New South Wales. J Pediatr 2005; 147: 3 Suppl, S47-S50.

10 Robinson MR, Hermani G, Medina-Gomez C, et al. Population genetic differentiation of height and body mass index across Europe. Nat Genet 2015; 47: 1357-1362.

11 Thomas M, Lemonnier L, Gulmans V, et al. Is there evidence for correct diagnosis in cystic fibrosis registries? J Cyst Fibros 2014; 13: 275-280. 